\title{
La cooperación en el Campo de Gibraltar tras el Brexit Nuevo marco para trabajadores fronterizos
}

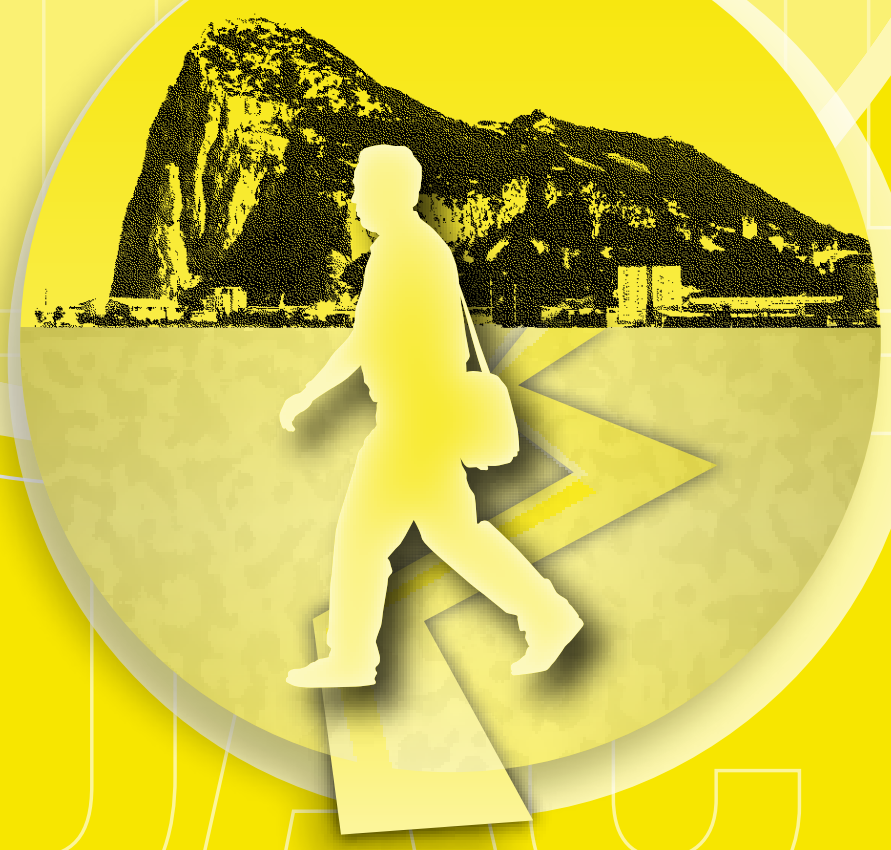


LA FUNDACIÓN CENTRO DE ESTUDIOS ANDALUCES ES UNA ENTIDAD DE CARÁCTER CIENTÍFICO Y CULTURAL, SIN ÁNIMO DE LUCRO, ADSCRITA A LA CONSEJERÍA DE LA PRESIDENCIA, ADMINISTRACIÓN PÚBLICA E INTERIOR DE LA JUNTA DE ANDALUCÍA. ENTRE NUESTROS OBJETIVOS FUNDACIONALES SE ESTABLECEN EL FOMENTO DE LA INVESTIGACIÓN CIENTÍFICA, LA GENERACIÓN DE CONOCIMIENTO SOBRE LA REALIDAD SOCIAL, ECONÓMICA Y CULTURAL DE ANDALUCÍA Y LA DIFUSIÓN DE SUS RESULTADOS EN BENEFICIO DE TODA LA SOCIEDAD.

NUESTRO COMPROMISO CON EL PROGRESO DE ANDALUCÍA NOS IMPULSA A LA CREACIÓN DE ESPACIOS DE INTERCAMBIO DE CONOCIMIENTO CON LA COMUNIDAD CIENTIIFICA E INTELECTUALY CON LA CIUDADANÍA EN GENERAL, Y A LA COLABORACIÓN ACTIVA CON LAS INSTITUCIONES PÚBLICAS Y PRIVADAS QUE INFLUYEN EN EL DESARROLLO DE LA COMUNIDAD AUTÓNOMA.

LA COLECCIÓN ACTUALIDAD FORMA PARTE DEL CATÁLOGO DE PUBLICACIONES CIENTIIFICAS DE LA FUNDACIÓN Y ESTÁ DESTINADA TANTO AL LECTOR ESPECIALIZADO COMO A LA OPINIÓN PÚBLICA EN GENERAL. CADA UNA DE SUS EDICIONES SE ESTRUCTURA COMO INFORMES MONOGRÁFICOS PARA EL FOMENTO DE LA REFLEXIÓN Y EL ANÁLISIS SOBRE ASPECTOS DE RELEVANCIA PARA LA SOCIEDAD ANDALUZA DEL SIGLO XXI.

LAS OPINIONES PUBLICADAS POR LOS AUTORES EN ESTA

COLECCIÓN SON DE SU EXCLUSIVA RESPONSABILIDAD.

(c) Del texto: sus autores, 2021

(c) De la edición: Fundación Pública Andaluza

Centro de Estudios Andaluces, mayo de 2021

Bailén 50, 41001 Sevilla.

Tel.: 955055 210. Fax: 955055211

www.centrodeestudiosandaluces.es

Depósito Legal: SE-1688-05

I.S.S.N.: 1699-8294

Ejemplar Gratuito. Prohibida su venta. 


\section{La cooperación en el Campo de Gibraltar tras el Brexit}

\author{
Nuevo marco para \\ trabajadores fronterizos
}

Inmaculada González García (IP) Alejandro del Valle Gálvez

Miguel A. Acosta Sánchez

Francisca Bernal Santamaría

Universidad de Cádiz

\begin{abstract}
Resumen
El Brexit ha impactado directamente en la relación de España con el Reino Unido (RU) por la cuestión de Gibraltar. La salida británica ha obligado a redefinir el estatuto europeo de Gibraltar, y sus relaciones con España y la Unión Europea (UE), en términos institucionales, jurídicos y económicos. En este contexto, también se han ideado unos mecanismos novedosos para regular y encauzar el tratamiento de la cooperación transfronteriza con Gibraltar, que ha tenido variadas e intermitentes fases en su planteamiento y evolución en el tiempo. En el marco del proceso de salida del RU de la UE se ha acordado un nuevo modelo en los sucesivos Tratados y acuerdos UE-RU que combinan Hard Law de Derecho originario con Soft Law de Memorandos de Entendimiento (Memorandum of Understanding$\mathrm{MoU})$. Esta regulación ha requerido de una negociación específica previa británico-española.
\end{abstract}

Destacaremos especialmente el primer Tratado de Retirada RU-UE de 2019, que ha conformado un auténtico sistema de cooperación transfronteriza que involucra al RU, la UE, Gibraltar y España, mediante una serie de Memorandos bilaterales hispano-británicos interconectados con el Protocolo sobre Gibraltar del Tratado, que a su vez reenvía al Tratado fiscal. Se trata de un nuevo sistema de cooperación concreta sobre derechos de los ciudadanos y trabajadores fronterizos, entre otras materias.

\section{Cooperation in the Gibraltar Area after Brexit}

\section{New framework for frontier workers}

Inmaculada González García (IP) Alejandro del Valle Gálvez Miguel A. Acosta Sánchez Francisca Bernal Santamaría University of Cadiz

\begin{abstract}
Brexit has directly impacted Spain's relationship with the UK due to the Gibraltar issue. The British withdrawal from the EU has forced the redefinition of the European statute of Gibraltar, and its relations with Spain and the European Union, in institutional, legal and economic terms. In this context, novel mechanisms have also been devised to regulate the treatment of cross-border cooperation with Gibraltar, which has had intermittent phases in its evolution over time. Within the framework of the British exit process, a new model has been agreed in successive EU-UK agreements that combine Hard Law (Primary EU Law) with Soft Law (Memoranda of Understanding-MOU). This regulation has required a specific prior BritishSpanish negotiation.
\end{abstract}

We will especially highlight the UK-EU Withdrawal Treaty of 2019, which has formed an authentic system of crossborder cooperation involving the UK, the EU, Gibraltar and Spain, through a series of Spanish-British bilateral Memoranda interconnected with the Protocol on Gibraltar of the Treaty, which in turn refers to the Tax Treaty. It is a new system of concrete cooperation on the rights of citizens and border workers, among other matters. 


\section{ÍNDICE}

Primera parte. El Brexit y la cooperación transfronteriza con Gibraltar

5

1. El Brexit, Gibraltar y España ............................................................................................................................

2. La controversia hispano-británica y las cuestiones de cooperación transfronteriza.....................................................6

3. El Tratado de Retirada de octubre de 2019 y la cooperación transfronteriza con Gibraltar .........................................8

4. El Tratado de relación futura UE-RU y el «Principio de acuerdo» España-RU de diciembre de 2020 para un separado y futuro Tratado RU-UE sobre Gibraltar ................................................................................................................. 10

Segunda parte. Los trabajadores fronterizos: régimen jurídico y protección social ..........................................11

5. Sobre la noción y características del «trabajador fronterizo».............................................................................................11

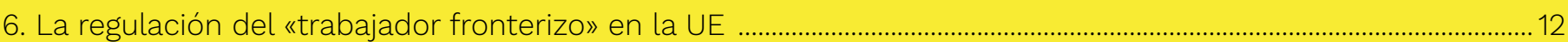

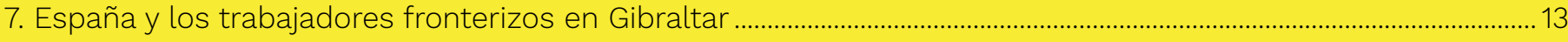

8. Regulación en el Tratado de Retirada y en el MOU sobre derechos de los ciudadanos ............................................14

9. El «Principio de acuerdo» España-RU y su impacto en los trabajadores fronterizos de Gibraltar .........................15

10. El proyecto de Ley de febrero de 2021 y su impacto en Gibraltar ....................................................................................16

11. Consecuencias del COVID-19 sobre los trabajadores fronterizos en Gibraltar.............................................................17

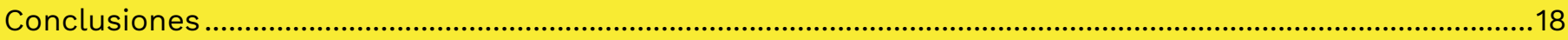

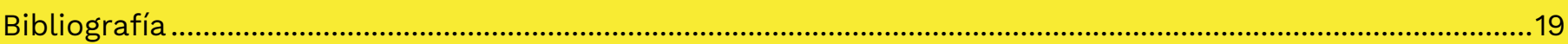

Publicación realizada en el marco del Proyecto de I+D «La incidencia del "Brexit" en la cooperación transfronteriza entre Gibraltar-Campo de Gibraltar y Andalucía», PRY2015/19 (IP: Inmaculada González García), seleccionado en la XI Convocatoria de Proyectos de Investigación de 2019 del Centro de Estudios Andaluces. La primera parte ha sido redactada por Alejandro del Valle Gálvez e Inmaculada González, Catedrático y Profesora Titular, respectivamente, de Derecho Internacional Público y Relaciones Internacionales (RRII) de la Universidad de Cádiz, siendo coautores de la segunda parte Miguel A. Acosta Sánchez, Profesor Titular de Derecho Internacional Público y RRIl y Francisca Bernal Santamaría, Profesora Sustituta del Departamento de Derecho del Trabajo y de la Seguridad Social, de la citada Universidad. 


\section{Primera parte. El Brexit y la cooperación transfronteriza con Gibraltar}

\section{El Brexit, Gibraltary España}

La salida del Reino Unido (RU) de la Unión Europea (UE), solicitada formalmente en marzo de 2017, ha supuesto una infinidad de cambios de planteamiento y de enfoque en materias europeas e internacionales. Este Brexit es un fenómeno histórico que ha afectado en la relación de España con el RU por la cuestión de Gibraltar.

En este sentido, la salida del RU de la UE ha implicado igualmente la salida de Gibraltar, en virtud del art. 355.3 del Tratado de Funcionamiento de la UE (TFUE), relativo al ámbito de aplicación de los Tratados de la UE, ya que las disposiciones de los Tratados se aplicaban a Gibraltar, en cuanto territorio europeo cuyas relaciones exteriores eran asumidas por un Estado miembro (el RU). Y es que Gibraltar no forma parte del Estado «Reino Unido de Gran Bretaña e Irlanda del Norte». Según el RU, este tiene soberanía sobre Gibraltar en virtud del art. X del Tratado de Utrecht de 1713 (por el que la Corona española cedió a la británica la ciudad y castillo de Gibraltar, juntamente con su puerto, defensas y fortaleza), y sobre el Istmo (por prescripción adquisitiva), pero no es un territorio integrado en el Estado británico. Por el contrario, es un territorio separado del $\mathrm{RU}$, atendiendo a la calificación interna que recibe en Derecho británico de territorio de ultramar (British Overseas Territory). Además, Gibraltar se encuentra en la lista de territorios no autónomos pendientes de descolonización en el marco de las Naciones Unidas, por lo que tiene un estatuto internacional diferenciado. Y en el seno de la UE, también ha venido teniendo Gibraltar un estatuto particular. En este sentido, la legislación comunitaria se ha aplicado en Gibraltar desde 1973 (tras entrar en la CE/UE con la adhesión del RU en 1972), con excepciones en los siguientes ámbitos materiales: Unión aduanera; libre circulación de mercancías; políticas comercial, agrícola y pesquera comunes; IVA; estando Gibraltar además fuera del Área Schengen por la no participación del RU en los Pactos de Schengen, siendo en consecuencia, de aplicación los controles de fronteras exteriores europeas con Gibraltar.

Pero el Brexit dio inopinadamente a España una posición favorable respecto a Gibraltar, que va a hacerla valer en los dos Tratados previstos para articular la salida del RU: un primer Tratado de Retirada del RU de la UE (Acuerdo sobre la retirada del Reino Unido de Gran Bretaña e Irlanda del Norte de la Unión Europea y de la Comunidad Europea de la Energía Atómica)', y un segundo Tratado de Relación futura UE-RU (Acuerdo de comercio y cooperación entre la Unión Europea y la Comunidad Europea de la Energía Atómica, por una parte, y Reino Unido de Gran Bretaña e Irlanda del Norte, por otra) ${ }^{2}$.

Para el Tratado 1 de Retirada, ya desde el primer momento de la negociación en 2017, España consiguió en las Orientaciones de negociación del Consejo Europeo la garantía de la Cláusula 24, consistente en que cualquier acuerdo sobre Gibraltar requiere el previo acuerdo entre España y RU; en la práctica excluye a Gibraltar de la lista negociadora y temas generales de negociación UE-RU. Además, con ocasión del Proyecto de Tratado de Retirada de noviembre 2018 se realizaron Declaraciones interpretativas que garantizaban en el futuro que la regulación sobre Gibraltar en el Tratado de relación futura UE-RU debía contar con la previa aquiescencia de España a cualquier nueva situación (y que una vez el RU hubiera abandonado la UE, Gibraltar no estaría incluido en el ámbito de aplicación de los acuerdos que se celebrasen entre la UE-RU). Incluso se ha introducido la situación colonial en las referencias a Gibraltar en diversos documentos de negociación.

Posteriormente, se confirmó esta necesidad de previo acuerdo de España en todo lo relativo a la relación UE-RU sobre Gibraltar: ocurrió

\footnotetext{
1 Este Tratado se refrendó en noviembre de 2018, siendo finalmente adoptado por las partes el 17-10-2019. Entró en vigor el 1-2-2020. DO, L, 29, de 31-1-2020. 2 Dicho Tratado fue acordado el 24-12-2020, si bien no ha sido aún ratificado ni ha entrado en vigor. DO L 444, de 31-12-2020.
} 
tanto para el Tratado 1 de Retirada de octubre de 2019 (del que forma parte integrante el Protocolo UE-RU anexo sobre Gibraltar, en el que aparecen referenciados los cuatro acuerdos bilaterales o Memorandos de Entendimiento -Memorandums of UnderstandingMoUs - que se firmaron por el RU y España, sobre derechos de los ciudadanos; tabaco y otros productos; cooperación en materia medioambiental; y cooperación policial y aduanera). Como también se ha reconocido para el Tratado 2 de Relación futura de diciembre de 2020 (que no se aplicará a Gibraltar ni tendrá efectos en dicho territorio), previéndose un Tratado separado UE-RU sobre Gibraltar. Precisamente para el futuro Tratado separado UE-RU hay un «Principio de acuerdo entre España y el RU sobre Gibraltar y sobre el Brexit» (en adelante, "Principio de acuerdo»), de 31 de diciembre de $2020^{3}$. Se trata de un «Entendimiento acerca de elementos fundamentales» para la relación futura UE y Gibraltar, que sirve para elaborar directrices de negociación de ese tratado específico RU-UE sobre Gibraltar, Tratado que ha de redactarse aún.

\section{La controversia hispano-británica y las cuestiones de cooperación transfronteriza}

En la historia de la controversia gibraltareña hemos vivido siempre, en el periodo democrático, una tensión o diferencia entre los aspectos de cooperación trasfronteriza con el entorno, por una parte, y la tradicional reclamación de la soberanía sobre la Ciudad perdida del Reino, por otra. Ambos aspectos están vinculados, y han conocido épocas de mayor o menor cooperación. Hoy se reconoce que los intereses de España son tanto la recuperación de la soberanía, como el bienestar y desarrollo de los españoles campogibraltareños, en una comarca de 300.000 personas, marcada y lastrada negativamente por la historia de la controversia.

\footnotetext{
3 Según la expresión exacta del Diario de Sesiones de las Cortes Generales, en la comparecencia de la ministra González Laya el 20-1-2021, Diario de Sesiones, Comisión Mixta UE, 2021 n. 42, XIV Legislatura, sesión n.․ 10 (extraordinaria) <https://www.congreso.es/public oficiales/ L14/CORT/DS/CM/DSCG-14-CM-42.PDF>.
}

En este contexto, la pertenencia del RU y España a la UE ha tenido una influencia muy importante en ambos aspectos de la controversia bilateral. Y es que el papel mediador o facilitador de la UE para limar las asperezas de la confrontación bilateral ha incidido especialmente en los aspectos prácticos de Derecho europeo que se han venido aplicando en Gibraltar y en el Campo de Gibraltar.

La controversia histórica hispano-británica sobre el Peñón de Gibraltar ha condicionado no sólo las relaciones bilaterales entre España y el RU en el seno de la UE, sino también la de los otros Estados miembros, en relación con la aplicación del Derecho de la UE en Gibraltar. Así, por ejemplo, los Estados miembros de la UE no mantienen ninguna comunicación directa con las autoridades de Gibraltar, debiendo realizarse todo a través de las autoridades británicas.

Y ello obedece, en buena parte, a la doctrina de las Naciones Unidas sobre la descolonización de Gibraltar, que prevé para tal fin un proceso negociado entre España y el RU, en el que se tendrán en cuenta los intereses y aspiraciones de Gibraltar. Dicho proceso bilateral se estableció en la Declaración de Bruselas de 1984, cuyo punto 1, c) vinculaba de forma expresa las cuestiones de soberanía con la cooperación transfronteriza en torno a Gibraltar. Una cooperación que persigue resolver los problemas causados por el hecho fronterizo y/o satisfacer los intereses comunes de las poblaciones que viven a uno y otro lado de la Verja/frontera —en materias como el medioambiente, la pesca, el transporte, la sanidad, en el ámbito deportivo, cultural o turístico, la cooperación judicial en materia civil, en materia fiscal, en la lucha contra los tráficos ilícitos, en el ámbito sociolaboral, entre otros-. 
Esta vinculación entre cooperación transfronteriza y controversia histórica sobre el Peñón ha dificultado, aunque no impedido, las iniciativas de cooperación transfronteriza entre las entidades territoriales subestatales españolas, por un lado, y el Gobierno de Gibraltar, por otro lado, siendo la espontaneidad una de las particularidades que tradicionalmente ha presentado la cooperación transfronteriza con Gibraltar. Esto es, la existencia de una práctica espontánea de cooperación, a través de la adopción de acuerdos de naturaleza política, principalmente, entre Gibraltar y el entorno del Campo de Gibraltar, ante la falta de un marco institucional y jurídico adoptado por los Estados.

No obstante, la creación el 16 de diciembre de 2004 por los Gobiernos de España, del RU y de Gibraltar del Foro de Diálogo sobre Gibraltar fue concebida como un cambio cualitativo de estrategia, al desvincular formalmente la cooperación transfronteriza de la controversia histórica sobre la soberanía del Peñón. En el marco de este Foro tripartito se adoptaron los Acuerdos de Córdoba de 2006 (sobre pensiones, uso conjunto del aeropuerto, mayor fluidez en el paso por la Verja/frontera, comunicaciones y la apertura del Instituto Cervantes), lo que vino a cubrir en el plano político la inexistencia de un marco jurídico regulador de las relaciones transfronterizas con Gibraltar, siendo un ejemplo de gentlemen's agreement (acuerdo entre caballeros) y de adopción de normas de Soft Law. También en 2004 se constituyó la «Comisión Mixta de Cooperación y Colaboración entre Gibraltar y la Mancomunidad de Municipios de la Comarca del Campo de Gibraltar», marco de cooperación de naturaleza local o subestatal, en la que se integró, el 12 de marzo de 2007, la Junta de Andalucía.

Pero los cambios de Gobierno en 2010-2011 que se sucedieron en el RU, Gibraltar, y muy especialmente en España, trajeron como consecuencia la suspensión del funcionamiento del Foro de Diálogo sobre Gibraltar (2004-2011) y con él, de los acuerdos que en su marco se fueron adoptando e incorporando en su agenda de trabajo, abriéndose una nueva etapa de bloqueo y falta absoluta de diálogo entre los Gobiernos de las partes principalmente interesadas en la cuestión de Gibraltar: en materia de soberanía a nivel interestatal (al quedar en suspenso el Proceso de Bruselas tras el fracaso de las negociaciones hispano-británicas sobre la cosoberanía de Gibraltar en 2001-2002), y en materia de cooperación transfronteriza (al no haberse podido sustituir el formato tripartito del Foro por un mecanismo ad hoc de cooperación regional cuatripartita en el Campo de Gibraltar, que contaría igualmente con la participación de los Estados y de la Comisión Europea, que sería invitada a participar como observadora).

Y es que, tras la crisis del verano de 2013 (que se inició con el lanzamiento por el Gobierno de Gibraltar de setenta bloques de hormigón en aguas que España reivindica bajo su soberanía, impidiendo a los pescadores españoles faenar en las mismas), y habiendo fracasado todos los intentos por establecer una cooperación estable mediante la creación de grupos ad hoc, cuatripartitos, etc., que permitieran que junto a las autoridades de Gibraltar estuvieran representadas al mismo nivel las autoridades regionales y locales de la zona circundante - Junta de Andalucía y Mancomunidad de Municipios de la Comarca del Campo de Gibraltar-, fue la sociedad civil la que se movilizó, creando por primera vez una iniciativa transfronteriza conjunta: el Grupo Transfronterizo-Cross Frontier Group, que cuenta con la participación de la Cámara de Comercio de Cádiz y Gibraltar; la Asociación de la pequeña y mediana empresa de La Línea y de Gibraltar; los sindicatos UGT/CC.OO.; el sindicato de funcionarios de Gibraltar-UNITE; y la CEOE (empresarios de Cádiz), que se unieron para plantear y hacer valer sus intereses comunes.

Precisamente en el seno del Grupo Transfronterizo se ha lanzado la iniciativa de la eventual creación de una Agrupación Europea de Cooperación Territorial (AECT), como entidad autónoma que gestione actividades y proyectos de colaboración conjuntos de Gibraltar y el Campo de Gibraltar. En efecto, la preocupación por la incidencia del Brexit en las relaciones socio-económicas entre Gibraltar y su Campo llevaron en 2015 a esta iniciativa de la sociedad civil, que cuenta con el apoyo de la Mancomunidad de Municipios de la Comarca del Campo de Gibraltar, de la Diputación de Cádiz y del Parlamento de Andalucía. No cabe duda de que esta figura de la AECT es posible preverla para la cooperación transfronteriza en el Campo de Gibraltar, ya que le era apli- 
cable el art. 355.3 TFUE, no estando excluida la legislación europea en materia de Cohesión Económica y Social y de Fondos estructurales -y de hecho se aplicaba en Gibraltar desde 1994, siendo objeto de un programa operativo FEDER en el marco del Acuerdo de Asociación RU-Comisión para el periodo 2014-2020, que expresamente integraba a Gibraltar junto a Escocia, Gales, Irlanda del Norte e Inglaterra-. Claro que las posibilidades de creación de una AECT con participación de entidades públicas de Gibraltar dejaría de ser entre dos Estados miembros, para estar constituida entre entidades de un Estado miembro (España) y de un tercer Estado no miembro (RU), de conformidad con el Reglamento AECT (art. 3 bis, atendiendo a la calificación interna que recibe en Derecho británico de British Overseas Territory, ya que Gibraltar no está en la lista de Países y Territorios de Ultramar del Anexo II TFUE).

En este sentido, la Junta de Andalucía (a través de la Secretaría General de Acción Exterior de la Consejería de la Presidencia, Administración Local y Memoria Democrática) presentó el 11 de mayo de 2018 al alcalde de La Línea de la Concepción y a representantes del Grupo Transfronterizo los borradores de estatuto y de convenio de la AECT, al estar integrada por la Junta de Andalucía, el Ayuntamiento de La Línea de la Concepción y el Grupo Transfronterizo, sin contar con la participación del Gobierno de Gibraltar. Ahora bien, aunque se anunció en febrero de 2018 que registraría acto seguido dicha iniciativa formalmente (la solicitud debe dirigirse a la Secretaría de Estado de Administraciones Públicas para la preceptiva autorización), lo cierto es que, a fecha de hoy, no hay constancia de que haya sucedido. Se trata de una iniciativa viable, que requería para su constitución del consentimiento de España y del RU, correspondiendo a España, país en el que se ubicaría el domicilio social propuesto de la AECT, la aprobación formal de su convenio constitutivo.

Con todo, se abre en el «Principio de acuerdo» de 31 de diciembre de 2020, como veremos luego, la posibilidad de un instrumento financiero específico para Gibraltar y el Campo de Gibraltar.

Desde 2012 hemos estado, por tanto, sin un formato institucional acordado para la cooperación transfronteriza con Gibraltar.

\section{El Tratado de Retirada de octubre de 2019 y la cooperación transfronteriza con Gibraltar}

La gran duda es ahora en este periodo del post-Brexit, el papel de la UE y de España con la salida del RU y el paso de Gibraltar a un estatuto internacional y europeo diferente.

La negociación del Tratado 1 de Retirada ha supuesto un gran revulsivo en las relaciones entre España y el RU en relación con Gibraltar, no sólo por reconocerse a España el papel esencial que hemos comentado para la aplicación del Derecho de la UE a dicho territorio (la garantía de la Cláusula 24 en las Orientaciones de negociación del Consejo Europeo de 29 de abril de 2017); también, por el reconocimiento expreso que se hace a las autoridades competentes (no sólo a las de Gibraltar, sino también a las de la zona circundante) en los Memorandos de Entendimiento hispano-británicos, así como en el Protocolo sobre Gibraltar adoptado por la UE y el RU.

Ahora bien, la única mención que el Tratado 1 de Retirada hace a Gibraltar está contenida en su art. 3.1, que establece su ámbito de aplicación territorial, incluyendo junto al RU otros territorios, como Gibraltar (en la letra b), en la medida en que el Derecho de la Unión fuese de aplicación a Gibraltar antes de la fecha de entrada en vigor del Tratado (siendo esta, el 1 de febrero de 2020). Ello planteó la necesidad de adoptar un Protocolo sobre Gibraltar (en noviembre de 2018), que establece una cláusula de salvaguardia en relación con las posiciones jurídicas de ambos Estados en relación con la soberanía y la jurisdicción de Gibraltar.

En este primer Tratado sobre la Retirada del RU de la UE, se ha querido focalizar en la cooperación transfronteriza con Gibraltar el tratamiento de la cuestión gibraltareña. La coyuntura del Brexit ha acentuado las problemáticas de la cooperación existente con el Campo de Gibraltar, y la necesidad de contar con los intereses de esta comarca; especialmente garantizar los derechos de los trabajadores transfronterizos, cuya defensa ha sido asumida por todas las fuerzas políticas espa- 
ñolas. Existe desde hace años, además, la perentoria necesidad de regular los problemas de la vida cotidiana y las cuestiones conflictivas más inmediatas con un Modus Vivendi con España, pues la comarca y el municipio fronterizo de La Línea viven día a día las consecuencias de la controversia histórica.

Con el precedente del Proyecto de Tratado de Retirada de 2018, cuyo Protocolo sobre Gibraltar ya obtuvo la aprobación de España en una separada negociación hispano-británica, el Tratado de Retirada en vigor contiene el Protocolo sobre Gibraltar, que reenvía, como hemos señalado, a cuatro Memorandos de Entendimiento sobre cooperación trasfronteriza, esencialmente: ciudadanos y trabajadores transfronterizos, tabaco, medioambiente, cooperación aduanera y policial. Igualmente, el Protocolo tiene en cuenta los temas luego regulados por el Acuerdo Internacional en materia de fiscalidad y protección de los intereses financieros entre España y el RU en relación con Gibraltar, hecho ad referendum en Madrid y Londres el 4 de marzo de 2019, y que ha entrado en vigor recientemente, el 4 de marzo de 2021, tras el proceso de ratificación llevado a cabo en ambos Estados4.

El Protocolo de Gibraltar y los cuatro Memorandos que se firmaron antes, en 2018, crean un sistema o formato institucional para la cooperación transfronteriza con los temas más urgentes a tratar, por lo que podemos afirmar que el necesario Modus Vivendi con Gibraltar ha sido conformado por el Derecho europeo con este Tratado de Retirada (más los MoUs). Llama la atención que en Derecho originario europeo (el Protocolo es parte integrante del Tratado de Retirada) se haya atendido con tanto detalle las cuestiones de cooperación transfronteriza relativas a Gibraltar. Se elevan así a rango de Derecho originario cuestiones esenciales de la cooperación transfronteriza en la comarca (como las materias reguladas en los MoUs y en el Tratado sobre fiscalidad y protección de intereses financieros), creándose además una estructura de seguimiento de estos acuerdos.

Lo anterior tiene el potente significado de blindar mediante Tratado internacional materias esenciales de cooperación con Gibraltar,

4 BOE n.o 62 de 13-3-2021 dando así el respaldo y amparo jurídico de la UE a este Modus Vivendi acordado previamente por España y el RU. Hay que resaltar que este blindaje legal que recibe la cooperación transfronteriza se ha conseguido gracias a la UE.

Además, hay en el Tratado de Retirada una serie de ideas que conviene destacar respecto a Gibraltar y el papel de la UE.

- Aunque se trata de instrumentos jurídicos diferentes (Protocolo del Tratado RU-UE, y MoUs hispano-británicos), el conjunto compone un marco jurídico institucional coherente y están bien trabados, gracias al reenvío institucional y a la referencia mutua de contenidos. Los MoUs prevén Comités y Grupos de Trabajo; y los Comités de los MoUs remiten información tanto al Comité especializado de Gibraltar (para las cuestiones relacionadas con la aplicación del Protocolo de Gibraltar), como al Comité Mixto RU-UE del Tratado de Retirada. A ello se une que el Tratado fiscal prevé un Comité conjunto de coordinación.

- Verdaderamente los derechos de los ciudadanos son los mejor preservados, ya que a esta parte del Protocolo no le afectará un Brexit duro. Esto tiene una lógica jurídica y política enorme, ya que el verdadero problema cotidiano de envergadura que puede plantearse es el del paso fronterizo de la Verja, ya que es absolutamente vital para Gibraltar y la comarca el flujo de trabajadores fronterizos residentes en España. En cambio, los contenidos de los MoUs y los comités de medioambiente y pesca, cooperación policial y aduanera, y tabaco, expiran el 31 de diciembre de 2020, «salvo que las partes acuerden otra cosa». Pero la lógica de favorecer una retirada ordenada, y la voluntad unánime de proteger los derechos de ciudadanos y trabajadores transfronterizos en el contexto socioeconómico de la comarca, abogaban por el mantenimiento de los MoUs incluso en el contexto de un Brexit duro.

- La combinación de Tratado (Derecho originario europeo) con Soft Law hispano-británico (los Memorandos de Entendimiento) se adapta bien a la realidad e intereses de las partes. Siempre se ha hecho uso de Soft 
Law en los acuerdos de España con RU sobre Gibraltar, pero este reconocimiento por la UE es una novedad aportada por el Tratado de Retirada, al conformar el nuevo formato de cooperación para Gibraltar.

- Se prevé la «mediación» de la UE en la controversia, institucional y materialmente. El entrelazamiento y vinculaciones entre Comités bilaterales UE-RU y España-UE ha conformado un auténtico sistema institucional para tratar los temas de Gibraltar, con participación y mediación de la UE.

\section{El Tratado de} relación futura UERU y el «Principio de acuerdo» España-RU de diciembre de 2020 para un separado y futuro
Tratado RU-UE sobre
Gibraltar

El Tratado segundo del Brexit (el de Relación futura UE-RU) de diciembre de 2020 no ha sido aún ratificado, si bien no regula la cuestión del estatuto de Gibraltar respecto a la UE y al Derecho de la UE ${ }^{5}$. En este sentido, se ha previsto un especifico y separado acuerdo UE-RU sobre Gibraltar. Es decir, que a partir de la entrada en vigor del Tratado 2 de comercio y cooperación entre UE-RU, y del Tratado específico UE-RU sobre Gibraltar, se establecerá una relación a largo plazo entre Gibraltar y la UE con vocación de permanencia y estabilidad.

Claro que, en aplicación de lo acordado al inicio de la negociación del Brexit, España y el RU deben llegar a un acuerdo antes de que la UE adopte cualquier decisión y acuerdo UERU. Se trata de la aplicación de las previsiones acordadas en noviembre de 2018 con ocasión del Tratado 1, ya que se mantiene la necesidad de un acuerdo previo entre España y el RU para cualquier acuerdo posterior entre la UE y el RU sobre el futuro de la relación de Gibral-

\footnotetext{
5 Se señala en la Séptima Parte de Disposiciones Finales, Artículo FINPROV.1: Ámbito territorial - «3.- El presente Acuerdo no se aplicará a Gibraltar ni tendrá efectos en dicho territorio.»
}

tar con la UE. De ahí la importancia del «Principio de acuerdo» de 31 de diciembre de 2020 acordado entre España y el RU sobre Gibraltar, y su nuevo estatuto europeo y de relación con España ${ }^{6}$.

En este documento informal (Non-Paper), transmitido a las autoridades comunitarias en Bruselas, se consiguen importantes acuerdos de cara al futuro. En resumen, podemos destacar estas ideas del «Principio de acuerdo»:

- El título («Principio de acuerdo entre España y el RU sobre Gibraltar y sobre el Brexit») engloba en realidad una serie de documentos. Se trata de un Working Paper con el título «Letters regarding a proposed framework for a UK-EU legal instrument setting out Gibraltar's future relationship with the EU»? ${ }^{7}$. Consiste en una carta de las Representaciones Permanentes (REPER) de España y del RU ante la UE, de 31 de diciembre de 2020, que anexan un NonPaper, con 25 estipulaciones y 3 Anexos.

- Este Working Paper es entonces el marco que acuerdan los dos Estados para el futuro Tratado RU-UE sobre Gibraltar, y que además debe ir acompañado de otros instrumentos de Soft Law que se refieren en el Non-Paper.

- En cuanto a los contenidos, destaca todo lo relativo a movilidad y tránsito por el paso fronterizo de la Verja, con una mayor parte de artículos y anexos dedicados a la circulación de ciudadanos y de trabajadores fronterizos.

- En este contexto, lo más llamativo es la integración del territorio de Gibraltar en el Área Schengen, lo que ha sido interpretado como demoler o derribar la Verja de Gibraltar (removing all physical barriers), y el establecimiento de puntos de entrada en el Área Schengen en el puerto y aero-

\footnotetext{
6 Conferencia de Prensa de la ministra de Asuntos exteriores de 31-12-2020, «González Laya anuncia un principio de acuerdo con Reino Unido sobre Gibraltar para derribar La Verja», El Economista, 31-12-2020. Un reportaje completo sobre esta comparecencia y el acuerdo, en EuropaSur, 1-1-2021, «España y Reino Unido redefinen la relación con Gibraltar en un acuerdo histórico». El Acuerdo fue publicado por el diario El País el 11-1-2021, y puede verse como Documentación VI del n.? 4 de los Cuadernos de Gibraltar/Gibraltar Reports, 2021. 7 Doc. Council WK 83/2021 INIT, de 5-1-2021.
} 
puerto. Esto conlleva una acción conjunta de FRONTEX (Agencia Europea de la Guardia de Fronteras y Costas) en estos puntos en los próximos 4 años, y la intervención española como Estado Schengen responsable, en una medida con cuestiones por concretar. También disposiciones sobre Visados y permisos de residencia.

- Otros aspectos que han sido objeto de acuerdo en el Non-Paper, aunque se refieren con menor intensidad, son los relativos a transporte, medioambiente, reglas uniformes (level playing field), datos, mecanismo financiero de cohesión, con una cláusula abierta para otros aspectos que se podrían incorporar.

Este «Principio de acuerdo» se tendrá en cuenta por la Comisión para el mandato negociador del específico Tratado de relación futura RU-UE sobre Gibraltar, mandato negociador aún no adoptado. Los contenidos esenciales nutrirán el futuro Tratado específico RU-UE sobre Gibraltar, que debe consagrarlos en su articulado, y pasar los necesarios controles parlamentarios para su aprobación antes de entrar en vigor, lo que se quiere que ocurra para junio de 2021.

El «Principio de acuerdo» detalla una clara voluntad de regular con permanencia una cooperación transfronteriza estable y normalizada de España para Gibraltar y el Campo de Gibraltar. Las cuestiones de soberanía han quedado aparcadas de momento, lo que permite esta regulación detallada de la cooperación deseable para un «futuro de prosperidad compartida» en el Peñón y la región circunvecina. No obstante, otro tipo de cuestiones vinculadas a la soberanía deben, en algún momento posterior, ser abordadas - de hecho, parece haber algún tipo de negociación para un acuerdo militar con el RU en la base de Gibraltar-.

\section{Segunda parte. Los trabajadores fronterizos: régimen jurídico y protección social}

En la Colonia de Gibraltar se calcula que existen actualmente entre 7.000 y 10.000 trabajadores fronterizos españoles, en su mayoría procedentes de los municipios del Campo de Gibraltar. Y se dedicarían a tareas relacionadas con la hostelería, el hogar, el cuidado de personas dependientes y la construcción y mantenimiento para pequeñas reparaciones y reformas, advirtiéndose en los últimos años un incremento de profesionales muy cualificados en el sector sanitario, técnicos e ingenieros informáticos, arquitectos, etc. La importancia de estos trabajadores se observa, además, en su considerable impacto en la economía de la zona. Conviene entonces determinar su régimen jurídico y los efectos a partir de la salida del RU de la UE.

\section{Sobre la noción y características del «trabajador fronterizo»}

La regulación de la figura del «trabajador fronterizo» tanto en el ámbito general como de la UE, presenta una serie de características muy particulares. Ello se debe a la falta de concreción o puesta en común sobre algunos aspectos esenciales en su propia definición y alcance.

Así, podemos identificar al trabajador fronterizo como aquella persona que, residiendo en la «zona fronteriza» de un Estado, desarrolla una actividad laboral en el territorio de otro Estado, volviendo a su lugar de residencia de forma diaria o semanalmente. A partir de esta definición podemos obtener hasta cuatro elementos constitutivos:

En primer lugar, el concepto de "zona fronteriza», constituido por una franja de territorio de un Estado limítrofe con otro Estado. Aquí encontramos una primera dificultad, pues como veremos, no existe unanimidad a la hora de determinar la extensión de dicha «zona fronteriza». 
En segundo lugar, se hace referencia a "una actividad laboral». Esta debe ser entendida como un trabajo por cuenta ajena, por ejemplo, el trabajador de una empresa de construcción, que se desplaza a otro país de forma diaria o semanal, para realizar su actividad profesional. Entonces, no entraría en la definición de «trabajador fronterizo» el que desarrolle una actividad por cuenta propia, lo que vendrían a ser las profesiones liberales (abogado, economista, asesor, etc.), formando parte de la categoría de «prestación de servicios».

En tercer lugar, encontramos un elemento territorial. Esto es, la necesidad de que se produzca un desplazamiento físico de un Estado a otro; en otras palabras, que se produzca el cruce de una frontera internacionalmente reconocida. Ejemplos: el trabajador español que se desplaza a Francia diaria o semanalmente; o el marroquí que entra con la misma periodicidad en Ceuta o Melilla.

Finalmente, en cuarto lugar, existe un elemento temporal: el regreso a su lugar de residencia, diaria o semanalmente. Así, si el desplazamiento se produce de forma permanente hasta la finalización de un trabajo determinado o por el tiempo acordado, no estaríamos ante la figura del «trabajador fronterizo», sino más bien del «trabajador desplazado».

\section{La regulación del «trabajador fronterizo» en la UE}

En el ámbito de la UE, los trabajadores fronterizos son considerados como una categoría de trabajadores y están cubiertos por las libertades del Mercado Interior. De esta for- ma, el trabajador fronterizo disfrutará de los siguientes derechos:

i) derecho de entrada en otro Estado miembro;

ii) derecho de estancia con la finalidad de buscar empleo;

iii) derecho de residencia durante todo el periodo de desarrollo de la actividad laboral;

iv) derecho de permanencia en el Estado donde ha realizado la actividad asalariada una vez que haya finalizado la misma.

A ello, se le debe añadir en materia de Seguridad Social el principio de territorialidad, de tal forma que se cotizaría en el Estado en el cual se ejerza la actividad económica.

No obstante, la normativa europea no es clara en cuanto al alcance de los elementos constitutivos de su definición.

De este modo, en el ámbito de la libre circulación de personas, cuando define al trabajador fronterizo, le exige una residencia de acogida durante un período mínimo de tres años ${ }^{8}$. Por su parte, en materia de Seguridad Social, en la definición se obvia el elemento territorial, limitándose al regreso al Estado de residencia de forma diaria o semanal ${ }^{9}$. En política fiscal, en cambio, se limita a indicar que el trabajador fronterizo deberá desplazarse en sus días de trabajo al otro lado de la frontera, sin distinguir si estos desplazamientos deben ser diarios o semanales ${ }^{10}$. Finalmente, sobre el concepto de "zona fronteriza», se oscila de una zona que no diste más de $30 \mathrm{~km}$ de la frontera (ampliable a $50 \mathrm{~km}$ ) en materia de

\footnotetext{
Vemos una general falta de unidad normativa sobre las definiciones de «trabajador fronterizo» y «zona fronteriza», dependiendo de la política en la cual nos encontremos, y sin tener en cuenta las posibles particularidades de cada caso
}

8 Directiva 2004/38/CE del Parlamento Europeo y del Consejo, de 29-4-2004, relativa al derecho de los ciudadanos de la Unión y de los miembros de sus familias a circular y residir libremente en el territorio de los Estados miembros por la que se modifica el Reglamento (CEE) n. ${ }^{\circ} 1612 / 68$ y se derogan las Directivas 64/221/CEE, 68/360/CEE, 72/194/CEE, 73/148/CEE, 75/34/CEE, 75/35/ CEE, 90/364/CEE, 90/365/CEE y 93/96/CEE, DO, L 158, de 30-4-2004.

9 Reglamento 2004/883/CE del Parlamento Europeo y del Consejo, de 29-4-2004, sobre la coordinación de los sistemas de seguridad social, DO, L 166, de 30-4-2004. 10 Directiva 2007/74/CE del Consejo, de 20-12-2007, relativa a la franquicia del IVA y de los impuestos especiales de las mercancías importadas por viajeros procedentes de terceros Estados, DO, L 346, de 29-12-2007. 
libre circulación de personas"1, por un lado, a una zona que no podrá exceder de $15 \mathrm{~km}$ en línea recta desde la frontera del Estado miembro, en materia fiscal, por otro lado ${ }^{12}$.

Vemos, por lo tanto, una general falta de unidad normativa sobre las definiciones de «trabajador fronterizo» y "zona fronteriza», dependiendo de la política en la cual nos encontremos, y sin tener en cuenta las posibles particularidades de cada caso, como sería la realidad en el Campo de Gibraltar. Así, aplicando de forma estricta la normativa reguladora de la "zona fronteriza», muchos municipios del Campo de Gibraltar quedarían excluidos de la aplicación del concepto de trabajador fronterizo. Véase, por ejemplo, un trabajador residente en Jerez de la Frontera que se desplace diariamente a Gibraltar a desempeñar una actividad laboral.

\section{España y los trabajadores fronterizos en Gibraltar}

La problemática que surge en el caso de los trabajadores fronterizos españoles en Gibraltar es que, realmente, no se cumple con el elemento territorial antes definido. Si recordamos, es necesario un desplazamiento físico del trabajador de un Estado (el de residencia) a otro Estado (el de acogida). Pero esto no ocurre en el caso de Gibraltar, dado que la Colonia no es un Estado independiente, sino un territorio no autónomo cuyas relaciones internacionales son asumidas por el RU. Este motivo, junto a la ya histórica reclamación española sobre Gibraltar, ha dificultado el reconocimiento de los derechos sociales de estos trabajadores por parte de las autoridades españolas.

Por otra parte, en Derecho español, la noción de «trabajador fronterizo» se ha identificado normalmente con aquel trabajador extranjero que viene a España a realizar una actividad laboral. De este modo, la primera referencia que

\footnotetext{
11 Reglamento 2006/1931/CE del Parlamento Europeo y del Consejo, de 20-12-2006, por el que se establecen normas relativas al tráfico fronterizo menor en las fronteras terrestres exteriores de los Estados miembros y por el que se modifican las disposiciones del Convenio de Schengen, DO, L 405, de 30-12-2006. 12 Reglamento 2009/1186/CE del Consejo, de 16-11-2009, relativo al establecimiento de un régimen comunitario de franquicias aduaneras, DO, L 324, de 10-12-2009.
}

encontramos es en la Ley Orgánica 4/2000 sobre derechos y libertades de los extranjeros en España, así como en su Reglamento de desarrollo por Real Decreto 557/2011'13, la cual exige que estos trabajadores fronterizos cuenten con una acreditación documental que les reconozca como tales.

Para encontrar una normativa que haga referencia a los trabajadores españoles en Gibraltar como «trabajadores fronterizos», si bien de forma indirecta y limitativa, debemos acudir a la política fiscal. De este modo, en la redacción de la Disposición Adicional 1.a de la Ley Orgánica 6/2011, en materia de lucha contra el contrabando ${ }^{14}$, se reducen a $80 \mathrm{ci-}$ garrillos las exenciones fiscales del IVA y de impuestos especiales para los «...trabajadores fronterizos de la zona fronteriza con Gibraltar...», entendiéndose como zona fronteriza el territorio hasta 15 kilómetros en línea recta a partir de la «frontera con Gibraltar». Ello incluiría a todos los municipios cuya demarcación, aunque parcial, se encuentren en dicha zona. Estamos entonces ante una normativa restrictiva a los trabajadores fronterizos, en la lucha contra el contrabando de tabaco, y que los discriminaría, por una cuestión de residencia en la «zona fronteriza», respecto del resto ${ }^{15}$. Otra cuestión sería establecer desde un punto de vista jurídico dónde se encontraría exactamente la «zona fronteriza con Gibraltar», encontrándonos con una clara discrepancia de interpretación entre las autoridades británico-gibraltareñas y las españolas.

En materia de cruce de fronteras, encontramos otra referencia a los trabajadores fronterizos. En efecto, por medio de la Resolución del 25 de julio de 2014, del Departamento de Aduanas e Impuestos Especiales de la

\footnotetext{
13 Ley Orgánica 4/2000, de 11 de enero, sobre derechos y libertades de los extranjeros en España y su integración social, BOE, núm. 10, de 12-1-2000, en particular art. 43; Real Decreto 557/2011, de 20 de abril, por el que se aprueba el Reglamento de la Ley Orgánica 4/2000, sobre derechos y libertades de los extranjeros en España y su integración social, tras su reforma por Ley Orgánica 2/2009, BOE, n. 103, de 30-4-2011, en particular art. 182. 14 Ley Orgánica 6/2011, de 30 de junio, por la que se modifica la Ley Orgánica 12/1995, de 12 de diciembre, de represión del contrabando, BOE, n. 156, de 1-7-2011, en su modificación por Ley 17/2012, de 27 de diciembre, de Presupuestos Generales del Estado para 2013, BOE, n.으 312, de 28-12-2012.

15 De hecho, aplicando de forma estricta esta normativa, municipios del Campo de Gibraltar como Tarifa o Jimena de la Frontera estarían exentos según la delimitación geográfica.
} 
Agencia Estatal de Administración Tributaria $(\text { AEAT })^{16}$, se ha buscado facilitar el cruce de los trabajadores fronterizos residentes en Gibraltar o en el territorio aduanero de la UE, siempre y cuando no tuvieran bienes a declarar ${ }^{17}$. En cualquier caso, era necesario su registro en la AEAT, previa presentación de su documento de identidad, contrato de trabajo y certificado de residencia. En la práctica, esta normativa ha sido muy poco eficaz, no solamente por el escaso porcentaje de trabajadores dados de alta en la AEAT, sino también por cuanto que no se está haciendo distinción entre las personas que atraviesan la Verja - sean o no trabajadores fronterizos - en dirección a España. De este modo, se produce un claro incumplimiento de la normativa tanto nacional como europea.

\section{Regulación en el Tratado de Retirada y en el MOU sobre derechos de los ciudadanos}

Como hemos visto, el Tratado 1 de Retirada establece la aplicación territorial del mismo, igualmente, a Gibraltar (art. 3), así como a los trabajadores fronterizos (art. 10.1c). Estos trabajadores deberán registrarse a través de un documento gubernamental que así lo acredite (art. 26). Esta obligación de registro ya venía prevista en la normativa española, recogida, concretamente, en la LO 4/2000, y más específicamente a efectos fiscales en relación con Gibraltar, en la Resolución de julio de 2014 de la AEAT.

En concreto, el Memorando sobre derechos de los ciudadanos (firmado el 29 de noviembre de 2018, junto al resto de MoUs, activándose en el momento en el cual entró en vigor el Tratado de Retirada el 1-2-2020)

\footnotetext{
16 Resolución de 25-7-2014, del Departamento de Aduanas e Impuestos Especiales de la Agencia Estatal de Administración Tributaria, por la que se regula el supuesto especial de uso del circuito rojo en el tráfico de viajeros en la Administración de Aduanas e Impuestos Especiales de la Línea de la Concepción para los trabajadores fronterizos, BOE, n. 183, de 29-7-2014.

17 Esta facilitación de cruce va en consonancia con lo previsto en el Anexo VII del Código de Fronteras Schengen, sobre trabajadores fronterizos. Ver Reglamento 2016/399/UE del Parlamento Europeo y del Consejo, de 9-3-2016, por el que se establece un Código comunitario de normas para el cruce de personas por las fronteras (Código de fronteras Schengen), DO, L 77, de 23-4-2016.
}

prevé la creación de un Comité de Coordinación bilateral tendente a garantizar el reconocimiento de derechos a los trabajadores fronterizos residentes en la «Mancomunidad de Municipios del Campo de Gibraltar» y el intercambio de información trimestral entre las autoridades, en aplicación de lo previsto en el Tratado de Retirada. El Comité de Coordinación se reunirá, al menos, una vez al trimestre, y está compuesto por parte española, por representantes del gobierno nacional, autonómico y local, y por parte británica, por representantes del RU y de Gibraltar. Lo que se pretende, en definitiva, es proteger los intereses de los trabajadores fronterizos españoles en Gibraltar, así como evitar graves perjuicios para el desarrollo socioeconómico de la zona, habiendo celebrado reuniones en febrero, julio y noviembre de 2020, a efectos de garantizar los derechos de los trabajadores fronterizos.

En esta perspectiva, y a la espera de lograr un acuerdo final, las autoridades de España, RU y Gibraltar, acordaron un procedimiento para garantizar los derechos de los trabajadores fronterizos a partir del 1 de enero de 2021, aplicando en esencia lo previsto en el Tratado de Retirada. Así, se establece un procedimiento de registro de estos trabajadores a través de las autoridades gibraltareñas ${ }^{18}$, como mecanismo de control para asegurar los derechos hasta ese momento reconocidos.

En el ámbito concreto de protección de Seguridad Social, un aspecto importante del Tratado 1 de Retirada viene determinado por las remisiones que finalmente se establezcan en cuanto a «la coordinación de la seguridad social en relación con los trabajadores residentes en España y empleados en Gibraltar, y los residentes en Gibraltar y empleados en España». Y ello en línea con lo establecido en el artículo 1 del Protocolo sobre Gibraltar, que reclama que las relaciones entre España y el RU deben quedar presididas por la cooperación, con el fin de garantizar los derechos de los ciudadanos, especialmente, de los trabajadores fronterizos que residen en Gibraltar o en España (y, en particular, en los municipios de la Mancomunidad del Campo de Gibraltar).

18 https://frontierworkers.egov.gi/ 
9. El «Principio de acuerdo» España-RU y su impacto en los trabajadores fronterizos de Gibraltar

En el Tratado 2 de Relación futura UE-RU no se indica nada sobre los trabajadores fronterizos. Para ello, debemos acudir al «Principio de acuerdo entre España y el RU sobre Gibraltar y sobre el Brexit» de 31 de diciembre de 2021, según el cual, la Colonia pasaría a formar parte del espacio Schengen, lo que supone reconocer la eliminación de cualquier frontera interna entre los territorios. En la práctica, ello implica la libertad de entrada y salida de la Colonia desde territorio español; en otras palabras, desaparece la Verja como punto de control fronterizo.

En este «Principio de acuerdo» hay una referencia expresa a los «trabajadores fronterizos» en el Anexo 3. Según el mismo, se establece que su definición será lo más amplia posible, incluyendo tanto a trabajadores por cuenta propia (los autónomos o profesiones liberales) como ajena. Se va a mantener, por otra parte, el sistema de registro ya recogido en el Tratado 1 de Retirada, así como en la propia normativa española. Desde un punto de vista laboral, además, se garantiza una igualdad de derechos entre los trabajadores fronterizos y el resto de los trabajadores, eliminando cualquier restricción existente, además de mejorar la calidad laboral y de protección social de todos estos trabajadores.

En materia de Seguridad Social, el «Principio de acuerdo» establece que se incluirá un capítulo sobre la coordinación de Seguridad Social de quienes trabajen en Gibraltar y residan en España, y a la inversa. Así, viene a exponer que las disposiciones incluidas en dicho capítulo podrían ser similares a las del Tratado de relación futura UE-RU, y proporcionarán, como mínimo, el nivel de protección y de derechos para los trabajadores previstos en el Acuerdo de Retirada. A este tenor, es interesante acudir a lo previsto en el Anexo 2 del «Principio de Acuerdo», de forma concreta, al momento en el que se propone un futuro acuerdo sobre un régimen de Seguridad Social que sea de aplicación a las personas que, siendo nacionales de un Estado miembro de la UE, del RU, refugiados, apátridas o nacionales de terceros países, se encuentren en algunas de las situaciones que detalla el Anexo: la primera situación para las personas residentes en Gibraltar que inicien una actividad por cuenta propia o ajena en un Estado miembro de la UE a partir del 1 de enero de 2021; la segunda, para aquellas que inicien una actividad por cuenta propia o ajena en Gibraltar a partir del 1 de enero de 2021; una tercera, para las personas que reciban una prestación o una pensión vinculada o derivada de las actividades anteriores (recuérdese, por cuenta propia o por cuenta ajena, ya sea en un Estado miembro de la UE o en Gibraltar); y la última situación, para proteger a los miembros de la familia o supérstites de las personas incluidas en las situaciones anteriores.

Dicho Anexo propone un régimen normativo compuesto por las normas en materia de coordinación de seguridad social: el artículo 48 del TFUE, el Reglamento 2004/883/CE, y el Reglamento 2009/987/CE ${ }^{19}$. Con respecto a los nacionales de terceros países, y a los miembros de su familia y supérstites que cumplan con las condiciones de los Reglamentos, se les aplicará, respectivamente, el Reglamento 1971/1408/CEE ${ }^{20}$ y el Reglamento 2009/987/CE.

De un análisis del "Principio de acuerdo» se desprende que el Reglamento 2004/883/CE está llamado a tener un papel protagonista (recuérdese que es de forma temporal, pues viene a recoger medidas de carácter transitorio) en la coordinación de los sistemas de Seguridad Social en este régimen transitorio. Es más, el mismo «Principio de Acuerdo» propone que lo dispuesto se adapte a las modificaciones que se vayan operando sobre él y sobre el Reglamento 2009/987/CE.

\footnotetext{
19 Reglamento 2009/987/CE del Parlamento Europeo y del Consejo, de 16-9-2009, por el que se adoptan las normas de aplicación del Reglamento (CE) n.․ 883/2004, sobre la coordinación de los sistemas de seguridad social, DO, L 284, de 30-10-2009.

20 Reglamento 1971/1408/CEE del Consejo, de 14-6-1971, relativo a la aplicación de los regímenes de seguridad social a los trabajadores por cuenta ajena y a sus familias que se desplazan dentro de la Comunidad, DO, L 149 , de 5-7-1971.
} 


\section{El proyecto de Ley de febrero de 2021 y su impacto en Gibraltar}

Una vez descrito el ámbito de aplicación recogido en el Tratado 1 de Retirada y el «Principio de acuerdo», es conveniente acudir al último paso dado para la adaptación del RU como tercer Estado, tras la finalización del periodo transitorio, esto es, el proyecto de Ley de 5 de febrero de $2021^{21}$.

La necesidad de su regulación obedece al deseo de tutelar los intereses de los ciudadanos y de los operadores económicos que pueden verse afectados por el fin del periodo transitorio, al pasar a ser el RU un Estado tercero a todos los efectos, así como, a contrarrestar los efectos indeseados derivados del fin de dicho periodo transitorio.

Como se verá, nos centraremos en el marco de la protección social que dispensa este proyecto de Ley que comparte, de forma coherente, el mismo objetivo de protección social que el Real Decreto-ley 38/202022.

Una de las notas características de las relaciones entre la UE y el RU es que éstas quedan presididas por el principio de reciprocidad. De hecho, en el Preámbulo del proyecto de Ley se advierte que el mantenimiento en el tiempo de las situaciones jurídicas reguladas en el mismo se supedita al otorgamiento de un tratamiento recíproco por las autoridades del RU. Igualmente, advierte que la reciprocidad se verificará después de la entrada en vigor de esta futura norma (Considerando III). Así se desprende del artículo 3, cuando establece que se suspenderán las medidas si las autoridades competentes no conceden un tratamiento recíproco a las personas físicas o

21 Proyecto de Ley por la que se adoptan medidas de adaptación a la situación de Estado tercero del Reino Unido de Gran Bretaña e Irlanda del Norte tras la finalización del periodo transitorio previsto en el Acuerdo sobre la retirada del Reino Unido de Gran Bretaña e Irlanda del Norte de la Unión Europea y de la Comunidad Europea de la Energía Atómica, de 31-1-2020, Boletín Oficial de las Cortes Generales, núm. 41-1, de 5-2-2021. 22 Real Decreto-ley 38/2020, de 29 de diciembre, por el que se adoptan medidas de adaptación a la situación de Estado tercero del Reino Unido de Gran Bretaña e Irlanda del Norte tras la finalización del periodo transitorio previsto en el Acuerdo sobre la retirada del Reino Unido de Gran Bretaña e Irlanda del Norte de la Unión Europea y de la Comunidad Europea de la Energía Atómica, de 31-1-2020. BOE, núm. 340, de 30-12-2020. jurídicas de nacionalidad española en el RU o en Gibraltar en los ámbitos afectados.

En este orden, se destaca una excepción importante al principio de reciprocidad. Se trata del mantenimiento de las prestaciones por desempleo de los trabajadores fronterizos que se trasladan diariamente a trabajar a Gibraltar y que residen en España. Se ha incluido una medida específica con el fin de mantener el derecho a la prestación por desempleo hasta el 31 de diciembre de 2022. Esta medida se aplica sin la exigencia del requisito de la reciprocidad al que ya se ha hecho referencia. Ello se justifica por las peculiaridades que existen en torno a los trabajadores fronterizos de la Comarca del Campo de Gibraltar, e igualmente, cabría añadir, el contextualizarlas en la elevada tasa de desempleo que caracteriza a esta zona. Así, se persigue un fin muy concreto: que los trabajadores fronterizos que no estén cubiertos por el Tratado 1 de Retirada no queden desprotegidos cuando se dejen de aplicar los Reglamentos de Seguridad Social.

En relación con el acceso a las prestaciones por desempleo, el artículo 10 del proyecto de Ley establece que los periodos acreditados en cualquier Estado miembro de la UE y en el sistema de Seguridad Social británico, que hayan sido realizados hasta el 31 de diciembre de 2020, se consideran periodos cotizados para el acceso y para el cálculo de las prestaciones por desempleo o cese de actividad. Además, esta situación queda supeditada al principio de «residencia» tan característico de la prestación por desempleo, pues se exige que se mantenga el derecho a residir en España (conforme a los Reglamentos de Coordinación de Seguridad Social) y siempre que se haya cotizado en último lugar en España. No obstante, el proyecto de Ley no exige este requisito (el de haber cotizado en último lugar en España) a los ciudadanos de la UE que no están incluidos en el ámbito de aplicación del Tratado 1 de Retirada, y que se desplazan diariamente a Gibraltar para realizar una actividad laboral, manteniendo su residencia en España. Estos sujetos podrán acceder hasta el 31 de diciembre de 2022 a las prestaciones por desempleo de los periodos de seguro acreditados en Gibraltar, antes y después de la finalización del periodo transitorio. Eso sí, para los periodos de seguro acreditados o realizados en Gibraltar a partir del 1 de enero 
de 2021 se reclamará a las autoridades británicas correspondientes el reembolso de las prestaciones abonadas por España; y ello cuando se acuerde un instrumento internacional que establezca los mecanismos de colaboración necesarios para el reembolso y la concesión de prestaciones por desempleo a estos trabajadores.

Por último, haremos referencia a la Disposición Transitoria Única que recoge el proyecto de Ley, alegando razones de seguridad jurídica. Esta disposición cubre a los beneficiarios de prestaciones por desempleo en España que hayan sido autorizados a desplazarse al RU para realizar acciones de perfeccionamiento profesional o de búsqueda de empleo en el RU o en Gibraltar. Cabe advertir que tendrían que tener la autorización para exportar esta prestación antes del 1 de enero de 2021. En este sentido, el proyecto de Ley dispone que podrán continuar percibiendo las prestaciones por desempleo durante tres meses, siempre que los Servicios de Empleo británicos garanticen el mantenimiento de la inscripción de estas personas hasta el final del derecho inicialmente reconocido.

\section{Consecuencias del COVID-19 sobre los trabajadores fronterizos en Gibraltar}

Las terribles consecuencias derivadas del COVID-19 en 2020 han tenido igualmente un impacto en los trabajadores fronterizos y en el cruce de los mismos a través de la Verja. El estado de alarma iniciado el 14 de marzo de 2020 en España ha ido en paralelo al cierre del espacio Schengen, así como del movimiento de personas entre los Estados. No obstante, el cruce de los trabajadores fronterizos ha quedado excluido de estas restricciones, expresamente respecto a Gibraltar ${ }^{23}$. El propio confinamiento de Gibraltar decretado por su Primer Ministro, el 22 de marzo de 2020, provocó irremediablemente el cierre temporal de

23 Art. 1 de la Orden INT/270/2020, de 21 de marzo, por la que se prorrogan los criterios para la aplicación de una restricción temporal de viajes no imprescindibles desde terceros países a la Unión Europea y países asociados Schengen por razones de orden público y salud pública con motivo de la crisis sanitaria ocasionada por el COVID-19, BOE, n. 79 , de 22-3-2020. numerosos centros de trabajo, con la consiguiente paralización de la actividad laboral de los trabajadores fronterizos. Una vez que comenzó la desescalada a mediados del mes de mayo de 2020, se ha garantizado el acceso de estos trabajadores a Gibraltar.

Sin embargo, el nuevo decreto de estado de alarma en España tras el periodo estival ha ido en paralelo con el surgimiento de una nueva cepa británica, con tremenda incidencia en la Colonia y la llegada de la tercera ola de la pandemia. Por ello, el Ministerio del Interior español decretó a finales de diciembre de 2020 la limitación en la entrada a España desde Gibraltar, exceptuando, entre otros, a los trabajadores fronterizos ${ }^{24}$. Asimismo, el Gobierno gibraltareño ha adoptado el confinamiento general de la Colonia el 2 de enero de $2021^{25}$. E inmediatamente, el Gobierno de la Junta de Andalucía ha decretado el cierre perimetral de ocho municipios de la comarca ${ }^{26}$, afectando a un total de 270.000 habitantes, en general, y a los trabajadores fronterizos, en particular.

Y es que el confinamiento ha llevado al cierre temporal de numerosos establecimientos comerciales y de servicios, con un importante impacto en la situación de los trabajadores fronterizos, tal y como sucedió en marzo de 2020. Por lo que observamos, en definitiva, la necesidad de medidas proteccionistas particulares para dichos trabajadores, que deberían surgir de una cooperación idónea entre las autoridades de ambos lados de la Verja.
24 Orden INT/1236/2020, de 22 de diciembre, por la que se establecen criterios para la restricción temporal del acceso por vía terrestre al espacio Schengen a través del puesto de control de personas con el territorio de Gibraltar por razones de salud pública con motivo de la crisis sanitaria ocasionada por el COVID-19, BOE, n. 333, de 22-12-2020.

25 HM GOVERNMENT OF GIBRALTAR, COVID-19 Lockdown Press Conference: Chief Minister's Script - 2/2021, de 2-1-2021.

26 En concreto, Tarifa, Algeciras, Castellar de la Frontera, Jimena de la Frontera, San Martín del Tesorillo, San Roque, La Línea de la Concepción y Los Barrios. Ver, Decreto de la Presidencia 1/2021, de 2 de enero, BOJA extraordinario, n.․ 1, de 2-1-2021. 


\section{Conclusiones}

El Brexit ha alterado favorablemente el marco jurídico e institucional, así como las posibilidades de futuro en materia de cooperación transfronteriza entre Gibraltar y el Campo de Gibraltar, si tenemos en cuenta que el Protocolo sobre Gibraltar y los Memorandos de Entendimiento hispano-británicos blindan en Derecho originario europeo una cooperación estable transfronteriza con Gibraltar.

Un avance significativo se da en el reconocimiento como interlocutores válidos de las autoridades gibraltareñas. Y es que la búsqueda de soluciones a los problemas comunes de las poblaciones que viven en la zona fronteriza requiere el reconocimiento como interlocutores de las autoridades competentes (territoriales y regionales) situadas a uno y otro lado de la Verja/frontera. Por lo tanto, se hace imprescindible el diálogo con el Gobierno de Gibraltar, la Junta de Andalucía y la Mancomunidad de Municipios de la Comarca del Campo de Gibraltar, lo que viene a reconocer los MoUs con la creación de Comisiones Técnicas o Comités de Coordinación, integrados por las autoridades competentes.

De conformidad con el Reglamento AECT (2013) y el Real Decreto 23/2015, entendemos que la creación de la AECT-Campo de Gibraltar/Gibraltar es viable en el marco de la negociación del Brexit entre un Estado miembro de la UE (España) y un tercer Estado (el RU), siendo necesaria la autorización de España y del RU. Ahora bien, correspondería al Estado español, en cuyo territorio se previó el establecimiento de su sede, la aprobación de su convenio constitutivo, si bien la Junta de Andalucía, como entidad participante de la AECT, no ha presentado la solicitud de creación de

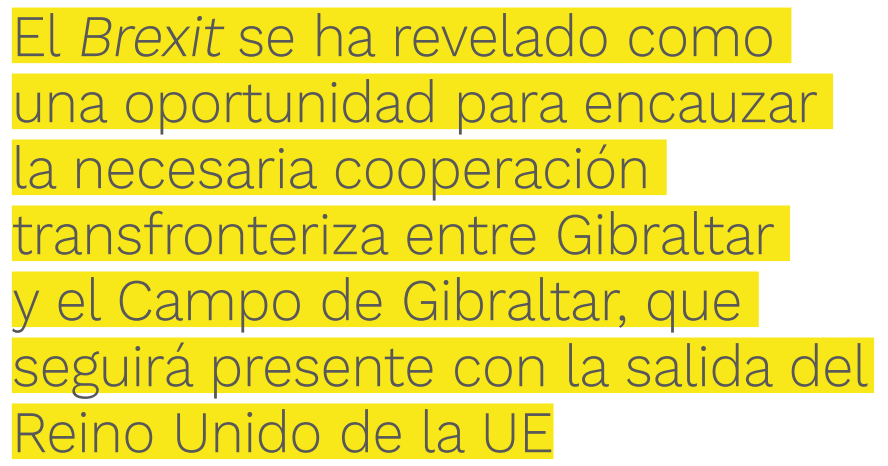

la misma en la Secretaría de Estado de Administraciones Públicas para su autorización. No obstante, se abre en el «Principio de acuerdo» (punto 23) la posibilidad de un instrumento financiero específico de Cohesión para Gibraltar y el Campo de Gibraltar.

De esta forma, el Brexit se ha revelado como una oportunidad para encauzar la necesaria cooperación transfronteriza entre Gibraltar y el Campo de Gibraltar, que seguirá presente con la salida del RU de la UE. Prueba de ello se da en relación con los trabajadores fronterizos, con una clara apuesta por mantener los derechos de los trabajadores fronterizos en Gibraltar. Por otra parte, con la entrada en vigor del Tratado de Retirada y el posterior acuerdo expreso sobre Gibraltar, se establece un marco de cooperación entre las partes a través del registro y verificación de los trabajadores fronterizos europeos en terceros Estados y viceversa. Todo ello conllevaría la creación de un interesantísimo panorama bilateral a fin de normalizar las relaciones en la zona.

Y en materia de Seguridad Social, los pasos legislativos que se han ido dando han tratado de garantizar una retirada ordenada del RU y de proporcionar una seguridad jurídica a todos los sujetos afectados. En aras de este objetivo, un fin es la protección social de las personas trabajadoras para que sigan ejerciendo sus derechos al amparo del ordenamiento jurídico que se venía aplicando. Se trata de medidas temporales y sujetas al principio de reciprocidad. La única excepción contemplada para el principio de reciprocidad se atiene a la prestación por desempleo. Así, y mientras no se tomen decisiones multilaterales o bilaterales de mayor calado, el impulso legislativo es mantener el nivel mínimo de protección que se ha venido ofreciendo. Y ello se hace principalmente con la adaptación del Reglamento 2004/883/CE, su reglamento de aplicación, entre otros instrumentos de coordinación de Seguridad Social.

Igualmente, es loable que se fomente la movilidad de personas trabajadoras, y se siga manteniendo el derecho de las prestaciones por desempleo (exportabilidad) a quienes hayan optado por ir al RU (o Gibraltar) a buscar activamente empleo o a mejorar su formación profesional, si bien limitado temporal- 
mente. Si se pretende seguir fomentando la movilidad y las relaciones entre el RU y la UE, es oportuno garantizar y velar porque siga existiendo una coordinación cada vez más estrecha y eficaz entre los regímenes de seguro de desempleo y los servicios de empleo de todos los países. En este punto, tiene sentido que se arbitren este tipo de medidas en un escenario de movilidad entre trabajadores para seguir fomentando la circulación de los trabajadores fronterizos en la Comarca del
Campo de Gibraltar, y de forma concreta, sus derechos de protección social.

Con el conjunto de estas previsiones, el futuro Tratado UE-RU sobre Gibraltar podrá garantizar un blindaje permanente de la cooperación transfronteriza en la práctica, con la presencia y mediación de la UE en el muevo marco convencional de cooperación entre el RU, Gibraltar y España.

\section{Bibliografía}

\section{ACOSTA SÁNCHEZ, MIGUEL A. (2017):}

«Gibraltar, trabajadores transfronterizos y controles en frontera», Cuadernos de Gibraltar/Gibraltar Reports, n.o 2, pp. 91-116.

\section{ACOSTA SÁNCHEZ, MIGUEL A. (2021):}

"Los trabajadores fronterizos en Gibraltar: el Brexit y más allá», en MARTíN RODRIGGUEZ, P. (dir.): Nuevo Mundo, Nueva Europa. La redefinición de la Unión Europea en la era del Brexit. XXVIII Jornadas de la Asociación española de Profesores de Derecho Internacional y Relaciones Internacionales. Valencia: Tirant lo Blanch, pp. 373-388.

\section{DEL VALLE GÁLVEZ, ALEJANDRO (2016): "Gibraltar, "año cero": Brexit, cosoberanía y nuevas oportunidades de España», Aná- lisis del Real Instituto Elcano, ARI 75 de 20-10-2016.}

\section{DEL VALLE GÁLVEZ, ALEJANDRO (2017):} «Brexit, Negotiations and Gibraltar: Time for a 'Modus Vivendi'?», Cuadernos de Gibraltar/ Gibraltar Reports, n.으 2, pp. 19-26.

\section{GARCIAA DE CORTÁZAR NEBREDA, CARLOS (2018): \\ «El brexit en el ámbito de coordinación de regímenes de seguridad social», Revista Ge- neral de Derecho del Trabajo y de la Seguri- dad Social, n.․ 49.}

\section{GONZÁLEZ GARCÍA, INMACULADA (2021):}

«El Brexity y la cooperación transfronteriza con Gibraltar: la creación de una Agrupación Europea de Cooperación Territorial (AECT)-
Campo de Gibraltar/Gibraltar», en MARTíN RODRÍGUEZ, Pablo (dir.): Nuevo Mundo, Nueva Europa. La redefinición de la Unión Europea en la era del Brexit, cit. supra, pp. 523-537.

\section{GONZÁLEZ GARCIA, INMACULADA Y ACOSTA SÁNCHEZ, MIGUEL A. (2020):}

"Las consecuencias del Brexit para Gibraltar», El Cronista del Estado Social y Democrático de Derecho, n. 84-85, pp. 82-91.

RODRIGUEZ CARDO, IVÁN ANTONIO (2011): «Trabajadores transfronterizos», en SÁNCHEZ-RODAS NAVARRO, Cristina (dra.): El Novísimo Reglamento de Extranjería. Murcia: Ed. Laborum, pp. 307-326.

\section{SANTA-BÁRBARA MARTÍNEZ, EUGENIO (2014):}

«Gibraltar, visiones desde este lado de la Verja. La incidencia socio-laboral de Gibraltar en la provincia de Cádiz: el flujo de trabajadores a través de la verja y su impacto en el Sistema Público español de Seguridad Social», Revista de Trabajo y Seguridad Social, n.. 375, pp. 105-154.

\footnotetext{
ZALVIDE BASSADONE, ALEJANDRO (2017): «Delimitación de la figura de trabajador fronterizo y su evolución conceptual en el panorama de la UE», en GORELLI HERNANDEZ, Juan (coord.): Libre circulación de trabajadores en la Unión Europea. Treinta años en la Unión. XXXV Jornadas Universitarias Andaluzas de Derecho del Trabajo y Relaciones Laborales. Sevilla: Consejo Andaluz de Relaciones Laborales, pp. 141-151.
} 


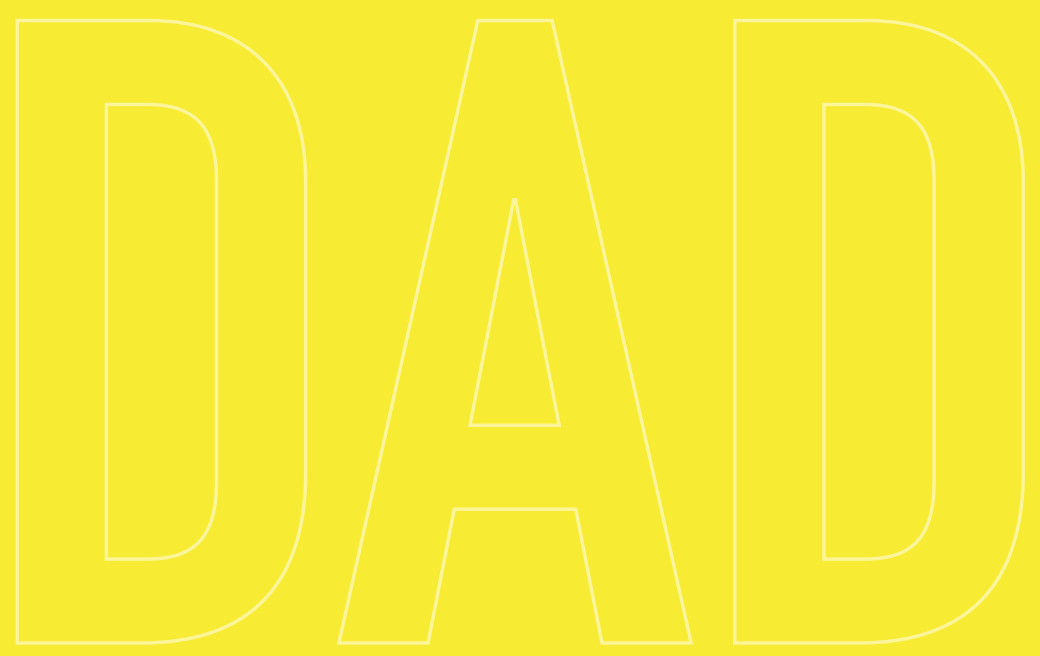




\section{NÚMEROS PUBLICADOS}

62: Las violencias masculinas y la prevención de la violencia contra las mujeres

63: La población infantil ante las nuevas tecnologías de la información. Una aproximación a la realidad de los nativos digitales andaluces

64: El contacto de la ciudadanía con los ayuntamientos como forma de participación política en Andalucía

65: Hacia un modelo de movilidad urbana sostenible

66: Las transiciones hacia el empleo de la juventud andaluza

67: El sector de los alimentos ecológicos en Andalucía: diagnóstico, retos y estrategias

68: Percepción de los españoles y andaluces ante la pobreza

69: La presencia de las mujeres en los ayuntamientos andaluces (1979-2011)

70: Un relato sobre identidad y vida buena en Andalucía

71: Bienestar, desigualdad y pobreza en Andalucía: un estudio comparativo con el resto de España a partir de las encuestas de condiciones de vida 2006 y 2012

72: Competencias autonómicas y gestión de la cuenca del Guadalquivir

73: Reformas legislativas, incumplimientos de la Carta Social Europea y su invocación en los órganos judiciales

74: Reforma constitucional y nuevo paradigma del Estado social. De la ordenación contingente a la organización consciente del bienestar

75: Bullying, cyberbullying y dating violence. Estudio de la gestión de la vida social en estudiantes de Primaria y Secundaria de Andalucía

76: ¿Odiamos la política?

77: Determinantes sociales de la salud en Andalucía

78: Líderes políticos y calendario electoral. Un análisis de la percepción de la población andaluza
79: La Renta Mínima de Inserción en Andalucía. Alcance y limitaciones

80: La edición independiente en Andalucía

81: Género y movilidad social: nuevos datos para Andalucía

82: Cambios en el comportamiento electoral en Andalucía. Análisis del ciclo electoral 2018-2019 (autonómicas, generales y municipales)

83: La cohesión territorial a través de la identidad nacional. El bienestar como elemento vertebrador de España

84: Brechas y sesgos de género en la elección de estudios STEM. ¿Por qué ocurren y cómo actuar para eliminarlas?

85: El reto de la longevidad en Andalucía. Causas, evolución y consecuencias

86: Nuevas tendencias en la vertebración de Andalucía. Territorio, población y familia en el siglo XXI

87: Democracia vs. desinformación. Propuestas para la protección de las sociedades abiertas

88: La crisis del coronavirus y la economía andaluza. Impacto, tendencias y recomendaciones

89: La respuesta de Europa a la crisis. ¿Está España protegida?

90: La respuesta política a la crisis en España y Andalucía

91: El perdón ante el acoso y ciberacoso escolar. ¿Por qué es tan importante entrenarlo en la adolescencia?

92: La descodificación de la agenda del COVID-19 en Andalucía

93: La libertad electoral en el mundo (2018-2020). España y Andalucía. Recomendaciones principales

94: La relevancia geoenergética de Andalucía para España y Europa

95: El aumento de personas mayores solas en Andalucía y España. Informe cuantitativo

96: La cooperación en el Campo de Gibraltar tras el Brexit. Nuevo marco para trabajadores fronterizos 
